\title{
EFFECTS OF CULTURE CONDITIONS ON MYCELIAL GROWTH AND LUMINESCENCE IN PANELLUS STYPTICUS
}

\author{
DAVID BERMUDES \\ Center for Great Lakes Studies, University of Wisconsin-Milwaukee, \\ 600 East Greenfield Avenue, Milwaukee, Wisconsin 53204 \\ VALerie L. Gerlach \\ Marquette University, Department of Chemistry, \\ Milwaukee, Wisconsin 53233 \\ AND \\ KeNNETH H. NEALSON \\ Center for Great Lakes Studies, University of Wisconsin-Milwaukee, \\ 600 East Greenfield Avenue, Milwaukee, Wisconsin 53204
}

\begin{abstract}
A pure culture of Panellus stypticus was isolated from a mature basidiocarp and studied for its growth and luminescence abilities under various environmental and nutritional conditions. The culture was non-luminous growing submerged in defined liquid media with or without agitation. After a two- to three-day lag period on solid substrata, luminescence increased exponentially with a doubling time of 4 hours while the increase in colony radial growth was linear. On solid substrata, growth and total light emission were strongly correlated under most conditions studied. Optimal conditions included darkness; $28 \mathrm{C}$; pH 3.8; glucose, maltose, trehalose, cellobiose or pectin as carbon source; and ammonia or asparagine as nitrogen source. Growth and luminescence were inhibited by ambient fluorescent light. Dark-grown colonies were brightest in the center while light-grown colonies were brightest at the periphery. Cultures hydrolyzed starch and produced an extracellular phenoloxidase. Conditions for production of luminescent basidiocarps by this culture are described.
\end{abstract}

Key Words: Panellus stypticus, luminescence, bioluminescence, defined media

Understanding the physiology of luminescent fungi and its relationship to light emission is important for several reasons. First, luminescence is rapidly and sensitively measurable in vivo and thus constitutes a endogenous reporter system that may help to reveal physiological interrelationships with environmental parameters. Second, expression of luminescence may be spatially resolved within a colony or basidiocarp and thus used as a marker for gene expression and differentiation. Finally, optimization of light emission by fungal cultures in the laboratory may aid in studies of its biochemistry.

Several quantitative studies of the physiology of fungal luminescence (e.g., Hastings, 1952; Airth and Foerster, 1960, 1965; Berliner, 1961a, b, 1963; Berliner and Brand, 1962; Foerster et al., 1965; Calleja and Reynolds, 1970a; Kamzolkena, 1982) and its biochemistry (Airth and McElroy, 1959; Airth and Foerster, 1962, 1964; Airth et al., 1966; Kuwabara and Wassink, 1966; Endo et al., 1970, Kamzolkena et al., 1983; Isobe et al., 1987, 1988; Nakamura et al., 1988; Shimomura, 1989) have been reported. However, the luminous fungus for which physiology in relationship to its light emission is best understood has been reported as $\mathrm{Col}$ lybia velutipes (Curt. ex Fr.) Kummer (= Flammulina velutipes (Curt. ex Fr.) Sing.) (Airth and McElroy 1959; Airth and Foerster, 1962, 1965; Foerster et al., 1965; Airth et al., 1966), although it is of dubious identity (Wassink, 1978). When strains of Flammulina velutipes obtained from the Culture Collection at the Center for Forest Mycology Research, University of WisconsinMadison (OKM 6261-sp) and by tissue culture were studied, neither basidiocarps nor mycelia 
produced measurable light (Bermudes, unpubl. observ.). Other species of Collybia are also apparently non-luminous [e.g., C. fusipes (Bull. ex Fr.) Quel. and C. tuberosa (Bull. ex Fr.) Kummer] as assayed by the naked eye (Bothe, 1931, cited in Harvey, 1952). Although we do not doubt the findings of the studies in which this fungus was used, as suggested by Wassink (1978), we henceforth refer to this species in quotations. Without knowledge of the species studied, the work necessarily cannot be reproduced and many interesting physiological data cannot be used. Further studies of the physiology of luminous fungi may help to resolve this problem.

Airth and Foerster (1965) found that ammonia or aspartic acid, glucose and $\mathrm{pH} 6.0$ were optimal for light emission and that their isolate of " $C$. velutipes" required the thiazole moiety of thiamine. Reports vary on the level of luminescence in liquid as opposed to solid substrate cultures. Airth (1961) and Wassink and Kuwabara (1966) found no luminescence in liquid (submerged) shake cultures of Armillaria mellea [= Armillariella mellea (Vahl in Fl. Dan. ex Fr.) Karst.] while Wassink and Kuwabara (1966) observed luminescence in submerged cultures of Panus stipticus [= Panellus stypticus (Bull. ex Fr.) Karst.], Mycena polygramma [= Mycena zephirus (Fr. ex Fr.) Kummer], and Omphalia flavida [= Mycena citricolor (Berk. \& Curt.) Sacc.] grown on bread crumb media. Calleja and Reynolds (1970b) reported that on agar substrata luminescence by Armillaria mellea and Panus stypticus occurred on all types of hyphae (primary, secondary, tertiary, aerial, superficial and submerged) at some time in their development but not in actively growing apices. Diurnal periodicity of luminescence was observed in P. stypticus, A. mellea and M. polygramma (Berliner, 1961a; Calleja and Reynolds, 1970a). Short-wave ultraviolet light $(280 \mathrm{~nm})$ reversibly inhibited $P$. stypticus luminescence while longer wavelength $(366 \mathrm{~nm})$ ultraviolet was stimulatory (Airth and Foerster, 1960; Berliner and Brand, 1962). In Armillaria mellea, $280 \mathrm{~nm}$ ultraviolet light stimulated luminescence (Berliner, 1963).

Strains of Armillariella mellea (GB 795-s and GB 895-s), Omphalotus olearius (DC ex Fr.) Sing. (900-22-s, HHB 7441-s, and HHB 2668-s) and Panellus stypticus (OKM-3787-s, T-79-s, and RLG-6828-s) from the Culture Collection at the Center for Forest Mycology Research, University of Wisconsin-Madison and strains of $P$. styp- ticus isolated by tissue culture were compared for overall luminescence on MsY agar. The highest level of light emission was produced by cultures of $P$. stypticus isolated by tissue culture (unpubl. observ.), although others have reported different relative intensities among various strains of these species (e.g., Berliner, 1961b). Here we report variations in growth and luminescence of $P$. stypticus under various culture conditions.

\section{MATERIALS AND METHODS}

Culture conditions. - Panellus stypticus (strain DB-Ps1 ATCC 66462) was obtained through tissue culture techniques as described by Molina and Palmer (1982) and maintained on MsY media consisting of molasses $(2.5 \% \mathrm{w} / \mathrm{v})$ and yeast extract $(0.5 \% \mathrm{w} / \mathrm{v})$ with $1.5 \%$ agar. This and other cultures were selected for visible luminescence. Quantitative measurements of luminescence were made on fungi grown on various media as described below.

Light measurements. - Luminescence was quantified by placing material in a light-tight housing with a $25 \mathrm{~mm}$ aperture positioned $2 \mathrm{~cm}$ over an EMI-type $9781 \mathrm{~A}$ phototube coupled to a Pacific Photometrics model 110 amplifier. Various housings were equipped to accept Petri dishes, culture tubes or scintillation vials. Fungal colonies were usually smaller than the photometer aperture, thus readings generally represent total luminescence of the colony. In cases where the colony expanded past the aperture opening, readings continued to be taken from the center of the colony. All measurements were made between 1200-1500 h. Light emission was calibrated using a radioactive light source as described by Hastings and Weber (1963). The emission spectrum maximum of the standard was $416 \mathrm{~nm}$ (fungal emission maxima are approx. $530 \mathrm{~nm}$; Spruit-van der Burg, 1950), and no correction for variation in spectral sensitivity was made. The limit of detection was $2.2 \times 10^{5}$ quanta (q)/ sec.

Photography. - Photography of luminescence was performed using Kodak Tri-X film in a Nikon camera with a $55 \mathrm{~mm}$ micro lens with aperture settings ranging from $\mathrm{f} 2.8$ to 8 . Exposure time ranged from $2-24 \mathrm{~h}$.

Light effects. - The effect of ambient fluorescent lighting on fungal light emission was determined by comparing cultures grown under darkened 
conditions with those grown under ambient light. Subsequently, dark-incubated colonies were exposed to ambient light and light-incubated colonies were darkened and the effect of these treatments measured.

Temperature effects. - Temperature optimum for both growth and luminescence was determined on dark-grown colonies. Colonies were grown under constant temperature conditions and colony size and total light output were determined. In addition, individual colonies grown at $22 \mathrm{C}$ were cooled and/or warmed at $2^{\circ}$ increments for 20 minute intervals to temperatures ranging from 4 to $38 \mathrm{C}$ using a water jacket housing mounted directly on the photometer.

pH optimum. - The effect of variables on luminescence were monitored on solid media, as $P$. stypticus does not luminesce in liquid cultures using defined media. Optimal $\mathrm{pH}$ was determined on both silica gel and agar substrata. Preliminary investigation showed that the $\mathrm{pH}$ optimum was below 4.2 and that agar did not solidify when autoclaved, presumably due to acid hydrolysis. Agar plates of low $\mathrm{pH}$ were prepared by autoclaving $100 \mathrm{mM}$ citrate-phosphate buffer ranging from 3.2 to 4.5 (McKenzie, 1974) and defined nutrients separately from the agar. The final $\mathrm{pH}$ of the media was recorded to the nearest tenth $\mathrm{pH}$ unit.

In order to be sure these results were not influenced by hydrolysis of the agar, silica gels were also used as a solid substratum. Potassium silicate was prepared following Funk and Krulwich (1964) using $10 \mathrm{~g}$ powdered silica gel (100-200 mesh) dissolved in $7 \% \mathrm{KOH}$ by heating on a hot plate and the volume adjusted to $100 \mathrm{ml}$ with additional $7 \% \mathrm{KOH}$. Batch equilibration of alkaline potassium silicate ( $\mathrm{pH}$ approx. 12) was performed by adding sufficient cation exchange resin (Biorad G $50 \mathrm{~W}-\mathrm{X} 4$ ) to bring $\mathrm{pH}$ to $\leq 10$, then removing the resin by filtration and adding back non-resin-treated potassium silicate to bring $\mathrm{pH}$ to 10 (Sommers and Harris, 1968). The resin was collected on a Buchner funnel using Whatman \#2 filter paper. The silica solution was measured into $50 \mathrm{ml}$ aliquots and autoclaved. During autoclaving the $\mathrm{pH}$ changed to approximately 9.8 and a small amount of precipitate formed which was removed by centrifugation. Subsequent autoclaving did not alter the $\mathrm{pH}$. To each $50 \mathrm{ml}$ aliquot of autoclaved, ion-exchange treated silicate, $25 \mathrm{ml}$ of $4 \times$-concentrated nutrient solution (see below) was added. $\mathrm{pH}$ was adjusted to the desired value using $20 \%$ phosphoric acid. Twenty-five $\mathrm{ml}$ of a $4 \times$ phosphate-citrate buffer was added to create a stable buffered $\mathrm{pH}$. This solution was poured into glass Petri dishes and autoclaved, at which time gelation occurred; media so prepared usually varied less than $0.03 \mathrm{pH}$ units.

Substrate utilization. - The effect of thiamine and utilization of various carbon and nitrogen sources by $P$. stypticus was studied using a defined variation of the MMN medium as described by Molina and Palmer (1982) lacking malt extract. The basal MMN medium consisted of $0.25 \mathrm{~g}$ $\left(\mathrm{NH}_{4}\right)_{2} \mathrm{HPO}_{4} 0.5 \mathrm{~g} \mathrm{KH}_{2} \mathrm{PO}_{4}, 0.15 \mathrm{~g} \mathrm{MgSO}_{4} \cdot 7 \mathrm{H}_{2} \mathrm{O}$ $0.05 \mathrm{~g} \mathrm{CaCl}_{2}, 0.025 \mathrm{~g} \mathrm{NaCl}, 1.2 \mathrm{ml}$ of $1 \% \mathrm{FeCl}_{3}$ solution per liter of distilled water. $\left(\mathrm{NH}_{4}\right)_{2} \mathrm{HPO}_{4}$ was omitted for the nitrogen source utilization study. Agar (Difco) at a concentration of $1.5 \%$ $\mathrm{w} / \mathrm{v}$, unless otherwise specified, was used as the solidifying agent for the medium. The basal medium was sterilized by autoclaving. Carbon and nitrogen sources were added aseptically by sterilization through a $0.22 \mu \mathrm{m}$ filter unless otherwise noted. Release of free glucose by autoclaved complex carbohydrates was determined colorimetrically using the glucose oxidase method (Sig$\mathrm{ma}$ ). Absorbance was measured at $505 \mathrm{~nm}$ with an LKB Ultrospec 4050.

Enzyme activity. - Ligninolytic and cellulolytic activities were assayed by growth on the above defined medium with cellulose as carbon source. Extracellular phenoloxidase activity, an indicator of ligninolytic activity, was tested for by the o-tolidene reagent described by Leslie and Leonard (1979) and by the addition of tannic acid (Fisher) at a concentration of $0.5 \mathrm{~g} / \mathrm{L}$ (Nicholson and Robinson, 1983). Starch hydrolysis activity was detected by flooding 4-week-old colonies on starch-containing agar plates with Gram-stain iodine (Smibert and Krieg, 1981).

Basidiocarp production. - A modification of the procedure for basidiocarp production by Pleurotus ostreatus (Jacq. et Fr.) Kummer described by Stamets and Chilton (1983) was utilized. The substrate consisted of a $15 \times 30 \mathrm{~cm}$ piece of corrugated cardboard weighing approx. $40 \mathrm{~g}$, rolled up tightly into a $15 \mathrm{~cm}$ high cylinder bound together with plastic coated electrical wire. The cardboard cylinder was placed into a quart-sized wide mouth canning jar and soaked with $100 \mathrm{ml}$ of MsY medium. Several holes were punctured 
MYCOLOGIA
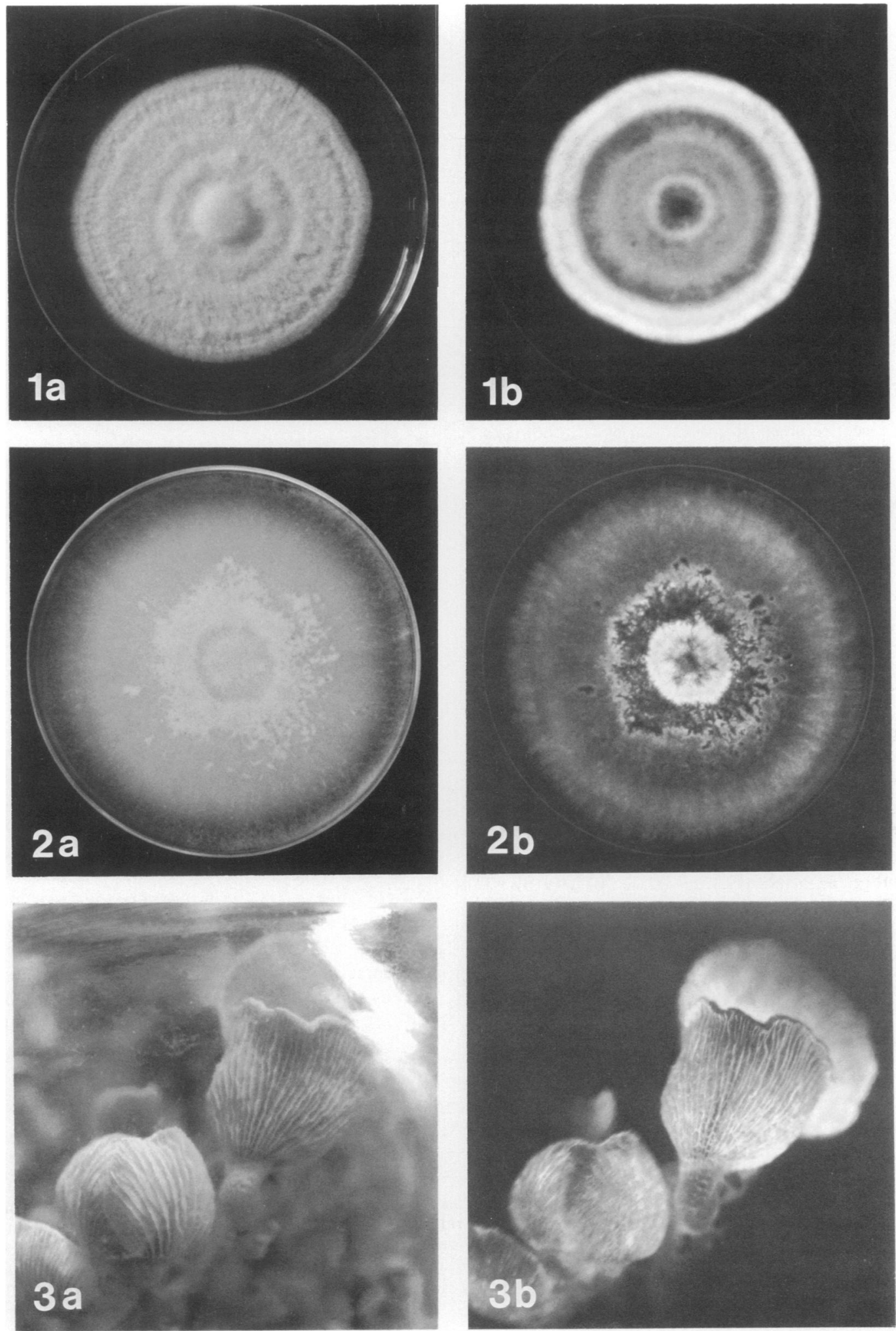
in the lid which was fitted with a non-absorbent cotton filter. This substrate was autoclaved and allowed to cool. Panellus stypticus grown in liquid media was aseptically homogenized by passage through a 16 gauge needle. Twenty $\mathrm{ml}$ of the mixture was uniformly introduced to the cardboard and incubated at $22 \mathrm{C}$ and $90 \%$ relative humidity for 4 weeks. The lids were then removed and several of the jars placed within a 10 gallon fish tank loosely fitted with a plexiglass top. Humidity was maintained between $80-85 \%$ at $13-18 \mathrm{C}$ by bubbling air through a water-containing beaker within the tank. A 15 watt fluorescent light placed $30 \mathrm{~cm}$ from the side of the tank was set to a $12 \mathrm{~h}$ dark/light cycle.

\section{RESULTS}

Culture characteristics. - Cultures were never luminescent when grown submerged on defined liquid media with or without agitation. However, on solid substrata, cultures were visibly luminescent. After transfer to a new substrate (MsY agar), there was a lag phase of 2-3 days, during which time luminescence often diminished below the limit of detection. Subsequently, luminescence increased exponentially with an average doubling time of approximately 4 hours while increase in radial growth proceeded linearly.

On agar plates, young colonies were uniformly luminescent while older colonies became differentiated. Older colonies grown under approximately $12 \mathrm{~h} \mathrm{light/dark}$ conditions formed concentric growth rings and showed maximum luminescence in one or two zones near the periphery of the colony, with the center considerably less bright (FIG. 1a, b). Colonies grown under dark conditions did not form conspicuous concentric growth rings and maintained the center of the colony as the brightest region of luminescence. However, they too had a zone of increased brightness near the periphery (FIG. 2a, b).

Light effects. - Dark-grown cultures of $P$. stypticus exhibited optimum temperature for lumi-
TABLE I

TEMPERATURE DEPENDENCY OF GROWTH AND LUMINESCENCE OF PANELLUS STYPTICUS UNDER DARK CONDITIONS $^{\mathbf{a}}$

\begin{tabular}{|c|c|c|c|c|}
\hline $\begin{array}{l}\text { Tem- } \\
\text { pera- } \\
\text { ture } \\
\left({ }^{\circ} \mathrm{C}\right) \\
\text { inten- } \\
\text { sity }\end{array}$ & $\begin{array}{c}\text { My- } \\
\text { celial } \\
\text { radial } \\
\text { growth } \\
\text { at } 11 \\
\text { days } \\
(\mathrm{mm})\end{array}$ & $\begin{array}{l}\text { Days to } \\
\text { maximal } \\
\text { light } \\
\text { intensity }\end{array}$ & $\begin{array}{c}\text { Maximal } \\
\text { light } \\
\text { intensity } \\
\left(\times 10^{5}\right. \\
q / \mathrm{sec})\end{array}$ & $\begin{array}{c}\text { Light } \\
\text { emission } \\
\left(\times 10^{5}\right. \\
\mathrm{q} / \mathrm{sec}) \text { per } \\
\mathrm{mm}^{2} \text { at } \\
\max .\end{array}$ \\
\hline 4 & 0 & $>17$ & 0 & 0 \\
\hline 13 & 2 & 17 & 4500 & 75 \\
\hline 16 & 3 & 15 & 24,600 & 276 \\
\hline 20 & 8 & 15 & 114,000 & 243 \\
\hline 22 (dark) & 10 & 15 & 222,000 & 315 \\
\hline 22 (light) & 9 & 17 & 138,000 & 192 \\
\hline 25 & 12 & 13 & 144,000 & 186 \\
\hline 28 & 13 & 11 & 108,000 & 165 \\
\hline 30 & 11 & 11 & 29,100 & 54 \\
\hline 33 & 2 & 7 & 48 & 1.2 \\
\hline
\end{tabular}

${ }^{a}$ MsY medium plus agar $2 \% \mathrm{w} / \mathrm{v}$.

nescence at $22 \mathrm{C}$ (TABLE I). However, luminescence of $22 \mathrm{C}$ cultures was increased $20 \%$ when the temperature of these cultures was raised to $28 \mathrm{C}$ (FIG. 4). Additional transient temperature increase lowered luminescence, suggesting that the lower luminescence at a sustained temperature of $28 \mathrm{C}$ was not due simply to inhibition of the enzyme system by high temperatures.

Growth under constant ambient fluorescent light at $22 \mathrm{Cled}$ to levels of luminescence reduced by $38 \%$ (TABLE I). Dark-grown cultures exposed to fluorescent light for 5 minutes showed a rapid increase in luminescence upon transfer to dark conditions (FIG. 5A). Emission was reduced 30\% by exposure to light with recovery to $97 \%$ of the initial level in $40 \mathrm{~min}$. Cultures exposed to fluorescent light for one hour showed an initial increase followed by a decrease and then a secondary increase (FIG. 5B). Cultures under fluorescent illumination for three hours initially showed decreased levels of emission and then increased emission by $30 \%$ within two h of being replaced in the dark (FIG. 5C).

Figs. 1-3. Growth forms and luminescence in Panellus stypticus. 1a. Culture grown under ambient light conditions on MsY agar exhibiting concentric growth rings. 1b. An autophotograph of the same culture showing the brightest luminescence at the periphery. 2a. Culture grown under dark conditions on MsY agar. Note the lack of concentric growth rings. $2 \mathrm{~b}$. Autophotograph of the same culture showing brightest luminescence at the center. 3a. Basidiocarps grown in the laboratory. 3b. Autophotograph of the same basidiocarps showing bioluminescence. 


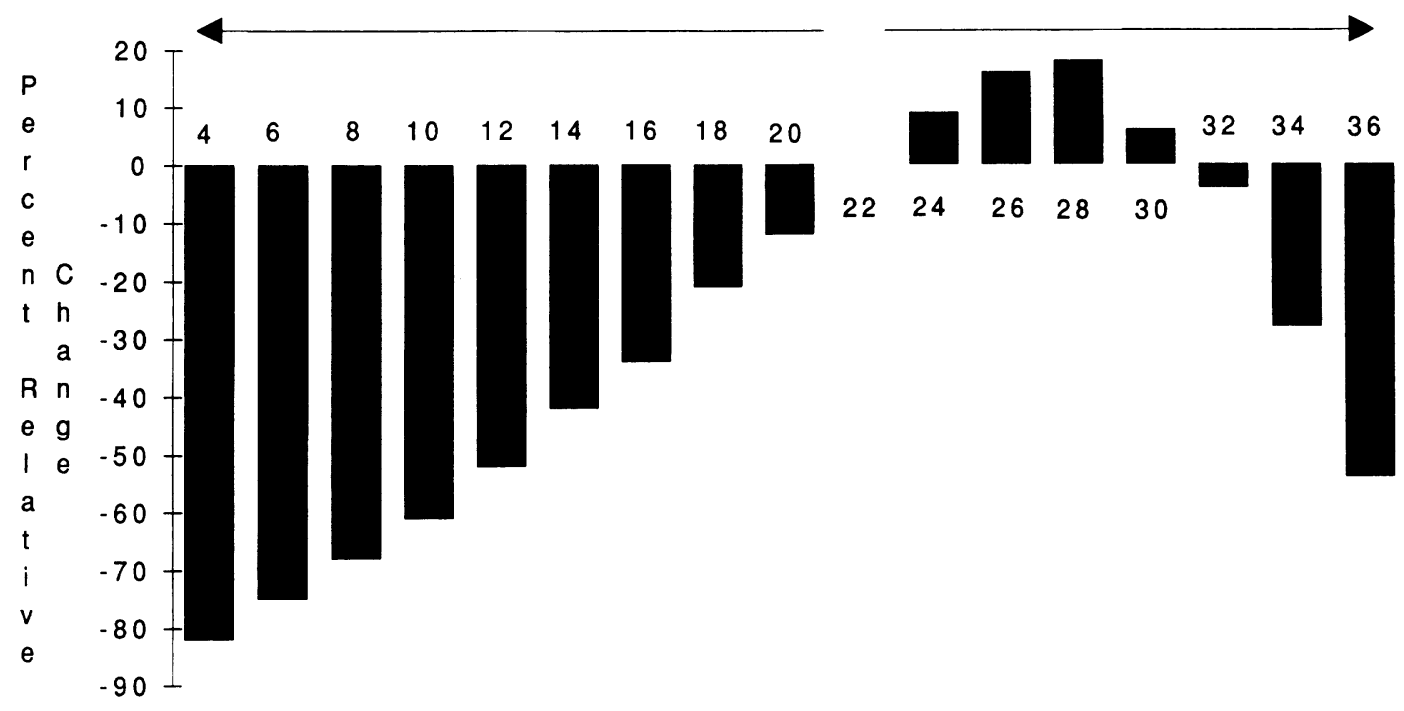

Temperature $\left({ }^{\circ} \mathrm{C}\right)$

FIG. 4. Effect of temperature shift on luminescence. Two separate cultures at $22 \mathrm{C}$ adjusted by means of the photometer shutter to an output of $2.5 \times 10^{8} \mathrm{q} / \mathrm{sec}$ were subjected to warming and cooling at 2 degree increments for 20 minute durations. Arrows indicate the direction of temperature shift (in degrees C).

pH optimum. - On silica gels, $P$. stypticus exhibited maximal luminescence and growth at $\mathrm{pH}$ 3.8 (TABLE II; FIG. 6). Silica and agar gels gave generally consistent results. Growth and luminescence were greatly reduced below 3.6 or above $\mathrm{pH} 4.4$, although specific luminescence (q/sec/ $\mathrm{mm}^{2}$ ) was not greatly affected; no growth or luminescence occurred at $\mathrm{pH} 6$ or above.

Substrate utilization. - Thiamine $\left(3 \times 10^{-7} \mathrm{M}\right)$ decreased growth rate and maximum luminescence on unbuffered glucose or cellulose substrata but increased both on unbuffered lactose and sucrose media.

Studies with various carbon sources revealed that pectin, lactose, maltose, glucose, cellobiose and trehalose gave high levels of luminescence while organic and amino acids were poor carbon substrata (TABLE III). Complex carbon sources were found to release low levels of free glucose when autoclaved making these experiments more difficult to control and evaluate. Although cultures grown on cellulose were weakly luminescent when compared to those grown on free sugars, growth persisted and often resulted in the production of basidiocarp primordia. Media lacking added carbon sources supported extremely sparse (yet widely extended) radial growth which gave very low levels of luminescence. This is probably due to the presence of organic contaminants in the agar.

Nitrogen source utilization is summarized in TABLE IV. Ammonium and L-asparagine were preferred substrata for both luminescence and growth. Low levels of luminescence were correlated with very sparse yet broad colonies.

Enzyme activity. - The P. stypticus culture possessed extracellular phenoloxidase activity as determined by the blue reaction with the o-tolidene reagent (Leslie and Leonard, 1979) and intense darkening in the Bavendamm test as described by Nicholson and Robinson (1983).

Basidiocarp production. - Bioluminescent basidiocarps were initiated 4 weeks after cardboard substrate inoculation. Many of the structures produced possessed incomplete caps. Fully formed mushrooms (FIG. 3a) were brightly luminescent (FIG. $3 \mathrm{~b}$ ) and produced viable spores which germinated into luminous mycelia. Luminous basidiocarps continued to be produced for 9 months.

\section{DISCUSSION}

As occurs in other fungi (Tan, 1978), light strongly influenced $P$. stypticus. Both growth and luminescence data show that ambient fluorescent 


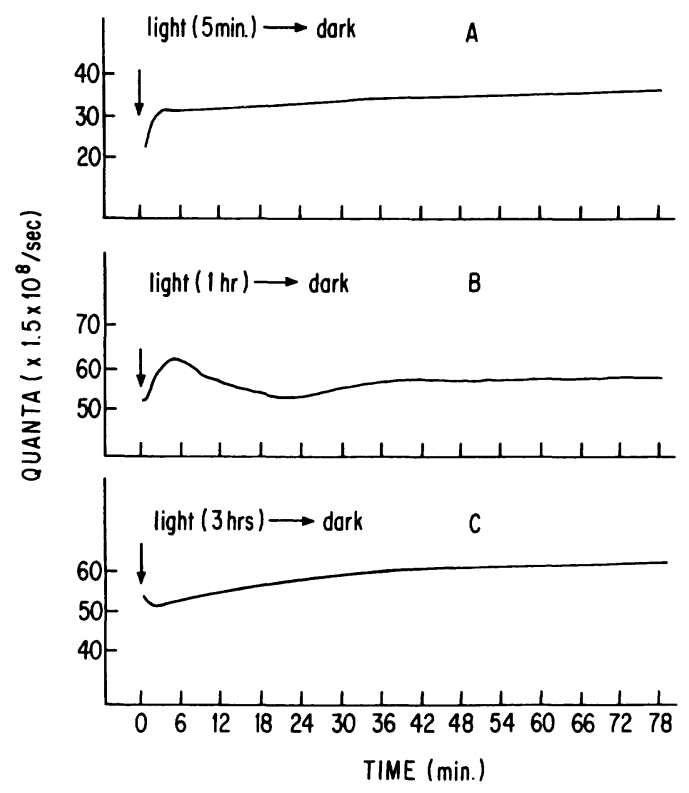

FIG. 5. Light and dark effects on light emission by 28-day-old cultures of Panelllus stypticus. 5A. A darkgrown culture on MsY agar exposed to fluorescent light for 5 minutes, then placed under dark conditions (arrow) and monitored for luminescence. 5B. A darkgrown culture on MsY agar exposed to fluorescent light for 1 hour, then placed under dark conditions (arrow) and monitored for luminescence. 5C. A dark-grown culture on MsY agar exposed to fluorescent light 3 hours, then placed under dark conditions (arrow) and monitored for luminescence.

light inhibits this fungus (TABLE 1) and caused variations in its pattern of luminescence (FIGS. $1,2)$. Young colonies, either light-grown or darkgrown, were relatively undifferentiated while older colonies exposed to the light had their brightest zone of light emission at the periphery and dark-grown colonies had their brightest zone at the center (FIGs. 1, 2). Unless utilization is made of small undifferentiated colonies unoccluded by the photometer aperture, quantitative measurement of light emission is complicated by the geometry of the photometer in use. Darkgrown colonies must be assayed without exposure to ambient light or they suffer considerable loss in their level of light emission although they quickly regain most of the initial level (FIG. 5A). Light-grown colonies must be assayed rapidly, as the photometer chamber represents a change to darkened conditions and an increase in luminescence occurs (FIG. 5B). The initial drop of luminescence after 3-hour exposure (FIG. 5C) may

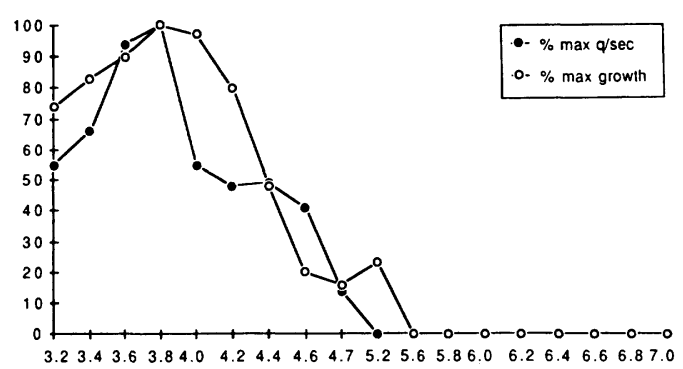

$\mathrm{pH}$

FIG. 6. Effects of $\mathrm{pH}$ on growth and luminescence of Panellus stypticus. Comparison of $\%$ maximum total luminescence and \% maximum growth at varying $\mathrm{pH}$. Based upon both agar and silica gel experiments.

have been due to decay of endogenous fluorescence (e.g., Cormier and Totter, 1966, or Lavelle et al., 1972, cited in Wassink, 1978) while the positive effect of darkening these colonies quickly ensues, causing the level to increase over a period of hours (FIG. 5C). Comparisons of light emission among fungi must be comparable in their previous light exposure conditions. Berliner and Brand (1962) found that UV light of $280 \mathrm{~nm}$ was particularly detrimental to luminescence of $P$. stypticus and suggested that it may involve a photolabile component of the luciferase system. The putative luciferin from Mycena citricolor isolated by Kuwabara and Wassink (1966) had an absorption maxima at 270 and $320 \mathrm{~nm}$. Although photolytic destruction of luciferin might

TABLE II

EFFECTS OF PH ON LIGHT PRODUCTION AND MYCELIAL GROWTH IN PANELLUS STYPTICUS ${ }^{\mathrm{a}}$

\begin{tabular}{|c|c|c|c|c|}
\hline $\mathrm{pH}$ & $\begin{array}{c}\text { Radial } \\
\text { growth } \\
\text { at } 14 \\
\text { days } \\
(\mathrm{mm})\end{array}$ & $\begin{array}{l}\text { Days } \\
\text { to } \\
\text { maxi- } \\
\text { mal } \\
\text { light } \\
\text { inten- } \\
\text { sity }\end{array}$ & $\begin{array}{c}\text { Maximal light } \\
\text { intensity } \\
\left(\times 10^{5} \mathrm{q} / \mathrm{sec}\right)\end{array}$ & $\begin{array}{c}\text { Light } \\
\text { emission } \\
\left(\times 10^{5}\right. \\
\mathrm{q} / \mathrm{sec}) \text { per } \\
\mathrm{mm}^{2} \text { at } \\
\text { max. } \\
\text { intensity }\end{array}$ \\
\hline 3.4 & 13 & 9 & 36,000 & 108 \\
\hline 3.6 & 18 & 9 & 51,000 & 87 \\
\hline 3.8 & 19 & 10 & 54,000 & 72 \\
\hline 4.0 & 13 & 7 & 50,000 & 132 \\
\hline 4.2 & 12 & 7 & 26,400 & 132 \\
\hline 4.4 & 9 & 7 & 26,700 & 150 \\
\hline 4.6 & 6 & 5 & 22,200 & 195 \\
\hline
\end{tabular}

a Medium: MsY; silica gel; citrate-phosphate buffer. $\mathrm{pH}$ after autoclaving was within 0.03 units of initial $\mathrm{pH}$. 
TABLE III

GROWTH AND LUMINESCENCE OF P. STYPTICUS GROWN ON VARIOUS CARBON SOURCES ${ }^{\mathrm{a}}$

\begin{tabular}{|c|c|c|c|c|c|}
\hline Carbon source & $\begin{array}{l}\text { Final carbon } \\
\text { concentration } \\
\text { (molar) }\end{array}$ & $\begin{array}{l}\text { Radial } \\
\text { growth } \\
\text { at } 14 \text { days } \\
(\mathrm{mm})\end{array}$ & $\begin{array}{l}\text { Days to } \\
\text { maximal } \\
\text { light } \\
\text { intensity }\end{array}$ & $\begin{array}{l}\text { Maximal light } \\
\text { intensity } \\
\left(\times 10^{5} \mathrm{q} / \mathrm{sec}\right)\end{array}$ & $\begin{array}{l}\text { Light intensity } \\
\left(\times 10^{5} \mathrm{q} / \mathrm{sec}\right) \\
\text { per } \mathrm{mm}^{2} \text { at } \\
\text { max. intensity }\end{array}$ \\
\hline None & nd & 19 & 5 & 900 & 3.0 \\
\hline Pectin* & unknown & 20 & 13 & 60,000 & 42 \\
\hline Lactose & 0.34 & 6 & 6 & 51,000 & 525 \\
\hline Maltose & 0.35 & 19 & 13 & 45,000 & 33 \\
\hline D-Glucose & 0.34 & 19 & 5 & 39,000 & 130 \\
\hline D-Cellobiose & 0.35 & 10 & 13 & 39,000 & 81 \\
\hline D-Trehalose & 0.31 & 21 & 4 & 39,000 & 153 \\
\hline D-Mannose & 0.34 & 21 & 11 & 21,300 & 18 \\
\hline D-Sorbitol & 0.33 & 16 & 4 & 16,500 & 93 \\
\hline Starch (Soluble)* & unknown & 20 & 12 & 14,400 & 11 \\
\hline D-Fructose & 0.34 & 39 & 14 & 13,500 & 2.4 \\
\hline Locust Bean Gum* & unknown & 20 & 11 & 11,700 & 11 \\
\hline D-Xylose & 0.34 & 18 & 11 & 11,100 & 12 \\
\hline D-Galactose & 0.34 & 17 & 14 & 9300 & 7.5 \\
\hline Gum Arabic* & unknown & 28 & 6 & 7500 & 11 \\
\hline Xylitol & 0.33 & 16 & 14 & 6600 & 5.7 \\
\hline Sucrose & 0.35 & 19 & 4 & 4800 & 21 \\
\hline Cellulose* & unknown & nd & 7 & 4200 & nd \\
\hline Glycerol & 0.33 & 18 & 4 & 1080 & 5.1 \\
\hline D-Mannitol & 0.33 & 17 & 12 & 1050 & 1.1 \\
\hline L-Serine & 0.28 & 14 & 14 & 1010 & 1.1 \\
\hline L-Proline & 0.44 & 17 & 4 & 990 & 5.1 \\
\hline DL-Threonine & 0.34 & 14 & 6 & 750 & 2.9 \\
\hline Pyruvic Acid & 0.27 & 4 & 4 & 57 & 1.1 \\
\hline Succinic Acid (pH 4.7) & 0.15 & nd & 4 & 30 & nd \\
\hline
\end{tabular}

${ }^{\text {a }}$ Medium is basal MMN plus carbon source, $1 \% \mathrm{w} / \mathrm{v}$; nitrogen source, $1.9 \mathrm{mM}\left(\mathrm{NH}_{4}\right)_{2} \mathrm{HPO}_{4}$; citrate-phosphate buffer: Final concentration citric acid $33 \mathrm{mM}, \mathrm{Na}_{2} \mathrm{HPO}_{4} 40 \mathrm{mM}$; agar, $1.5 \%$; pH $4.2 \pm 0.05$ unless otherwise noted. Carbon sources sterilized by filtration $(0.22 \mu \mathrm{m})$ except for those marked by asterisk, which were autoclaved.

nd $=$ not determined.

be expected to give brief reductions in the level of luminescence followed by recovery due to de novo synthesis, the cause and effect relationships of these facts are unknown.

Some luminescent fungi (Armillariella mellea, Mycena polygramma and Panellus stypticus) reportedly exhibit pronounced diurnal periodicity (Berliner, 1961a; Calleja and Reynolds, 1970a). In the investigation by Berliner (1961a), diurnal periodicity was not found in Armillaria fusipes (= Armillariella mellea), Clitocybe illudens $(=$ Omphalotus olearius), Mycena galopus (Fr.) Quélet, or Mycena citricolor. Maximum luminescence occurs between 6 and 9 PM regardless as to whether the cultures are incubated in continuous light, continuous darkness, or a normal day-night cycle. This fact makes it imperative that time of day be noted in day-to-day comparisons. Preferably, measurements are made at the same time each day. A single report on seasonal variation of luminescence in Armillariella mellea (Kamzolkena, 1982) further suggests the absolute need for simultaneously grown control cultures.

Absence of luminescence in liquid cultures on defined media creates several difficulties. Large quantities of luminescent mycelia are more difficult to obtain. Determination of $\mathrm{pH}$ optima requires solid substrata which entail special preparation. Further, the use of radial extension as an indicator of overall growth on such solid substrata is also problematical. While it gives results strongly correlated with maximal light intensities for the best substrata, the poorest substrata often have broad radial extensions with extremely diffuse hyphae, representing little biomass. This problem is somewhat rectified by determination of luminescence per unit area. 
TABLE IV

GROWTH AND LUMINESCENCE OF P. STYPTICUS GROWN ON VARIOUS NITROGEN SOURCES ${ }^{\mathrm{a}}$

\begin{tabular}{lccccc}
\hline Nitrogen source & $\begin{array}{c}\text { Final nitro- } \\
\text { gen source } \\
\text { concentration } \\
(\mathrm{mM})\end{array}$ & $\begin{array}{c}\text { Radial } \\
\text { growth } \\
\text { 14 days }(\mathrm{mm})\end{array}$ & $\begin{array}{c}\text { Days to } \\
\text { maximal light } \\
\text { intensity }\end{array}$ & $\begin{array}{c}\text { Maximal light } \\
\text { intensity } \\
\left(\times 10^{5} \mathrm{q} / \mathrm{sec}\right)\end{array}$ & $\begin{array}{c}\text { Light emission } \\
\left(\times 10^{5} \mathrm{q} / \mathrm{sec}\right) \\
\text { per } \text { mm }^{2} \text { at } \\
\text { max. intensity }\end{array}$ \\
\hline None & nd $^{\mathrm{b}}$ & 16 & 5 & 1110 & 4.5 \\
$\left(\mathrm{NH}_{4}\right)_{2} \mathrm{HPO}_{4}$ & 1.9 & 18 & 7 & 11,700 & 26 \\
L-Asparagine & 1.9 & 13 & 14 & 6900 & 8.7 \\
L-Leucine & 3.8 & 13 & 5 & 1050 & 5.7 \\
L-Isoleucine & 3.8 & 14 & 10 & 1010 & 1.9 \\
L-Histidine & 1.3 & 17 & 8 & 930 & 1.8 \\
DL-Threonine & 3.8 & 17 & 10 & 870 & 1.2 \\
L-Phenylalanine & 3.8 & 9 & 6 & 810 & 5.4 \\
DL-Valine & 3.8 & 20 & 4 & 750 & 3.3 \\
L-Methionine & 3.8 & 9 & 7 & 690 & 3.9 \\
L-Tryptophan & 1.9 & 5 & 5 & 330 & 4.5 \\
L-Arginine & 0.94 & 6 & 4 & 93 & 1.3 \\
L-Aspartic Acid & 3.8 & 4 & 4 & 63 & 1.2 \\
L-Lysine & 1.9 & 6 & 4 & 60 & 0.87 \\
\hline
\end{tabular}

a Medium: basal MMN (minus nitrogen) plus carbon source, $0.056 \mathrm{M} \mathrm{D}$-glucose; final concentration of nitrogen $3.8 \mathrm{mM}$; agar $2 \% \mathrm{w} / \mathrm{v} ; \mathrm{pH}=4.25 \pm 0.05$. Citrate-phosphate buffer: final concentration citric acid $29 \mathrm{mM}$, $\mathrm{Na}_{2} \mathrm{HPO}_{4} 42 \mathrm{mM}$. Carbon and nitrogen sources sterilized by filtration ( $0.22 \mu \mathrm{m}$ pore size).

${ }^{\mathrm{b}}$ nd $=$ not determined.

Species of luminescent fungi reviewed by Wassink (1978) are generally noted as occurring in wood-decay environments. Singer (1986) noted that $P$. stypticus is opportunistic in tree wounds. Thus it is not surprising that these fungi prefer glucose and similar sugars or polymers such as pectin as carbon sources. Based on cellulose utilization, cellulolytic activity is low in the strain studied (TABLE III) but is presumed to occur based on continued growth and luminescence of basidiocarps on cardboard substrata long after free sugars would be exhausted. Based on the presence of phenoloxidase activity, like its relative Panus tigrinus (Bull. ex Fr.) Sing. (Leslie and Leonard, 1979), Panellus stypticus is probably ligninolytic. However, radiolabeled lignin and cellulose degradation assays would be required to confirm these assumptions.

It is doubtful that $P$. stypticus studied here is the "Collybia velutipes" described by Airth and Foerster (1965; Foerster et al., 1965). Panellus stypticus has a pH optimum of 3.8, low for most fungi and did not grow at $\mathrm{pH} 6$ or above while "Collybia velutipes" did not grow at $\mathrm{pH}$ below 5 (Airth and Foerster, 1965). "Collybia velutipes" required the thiazol moiety of thiamine (Airth and Foerster, 1965) which is not required by $P$. stypticus although it enhanced growth and luminescence under some conditions. However, as deficiencies for thiamine are common among fungi (Moore-Landecker, 1972) they do not constitute a reliable taxonomic marker. Both fungi preferred glucose and ammonia, and each had a preference for a particular amino acid; L-aspartic acid for " $C$. velutipes" (Airth and Foerster, 1965) and L-asparagine for $P$. stypticus.

Panellus stypticus is among the most common and brightly luminescent North American fungi. It is easily grown on defined or undefined media and produces basidiocarps in culture on inexpensive substrata. It has been included in a number of studies on luminescence including some concerning its genetics (Macrae, 1937, 1942) and biochemistry (Airth and Foerster, 1964; Nakamura et al., 1988; Shimomura, 1989) and should be useful for further studies of bioluminescent fungi.

\section{ACKNOWLEDGMENTS}

This work was supported by the National Institute of Environmental Health Sciences National Service Research Award Grant \#ES 07043 and NASA Grant \#144Z212 for (DB) and the National Science Foundation Research Experience for Undergraduates (for VG). We thank Albert M. Boman for living specimens of Panellus stypticus and Martyn J. Dibben, Milwaukee Public Museum for their identification. We are grateful to Elizabeth Dorworth at the University of WisconsinMadison Center for Forest Mycology Research for pro- 
viding cultures of luminescent fungi. We also thank Rebecca Asbek and Jo Linda Denoyer from the University of Wisconsin-Milwaukee Young Scholars Program for assistance in photometric measurements.

\section{LITERATURE CITED}

Airth, R. L. 1961. Characteristics of cell-free fungal bioluminescence. Pp. 262-273. In: Light and Life. Eds., W. D. McElroy and B. Glass. The Johns Hopkins Press, Baltimore, Maryland.

- , and G. E. Foerster. 1960. Some aspects of fungal bioluminescence. J. Cell. Comp. Physiol. 56: $173-182$.

— and 1962. The isolation of catalytic components required for cell-free fungal bioluminescence. Arch. Biochem. Biophys. 97: 567-573. - and - 1964. Enzymes associated with bioluminescence in Panus stypticus luminescens and Panus stypticus non-luminescens. J. Bacteriol. 88: 1372-1379.

, and - 1965. Light emission from the luminous fungus Collybia velutipes under different nutritional conditions. Amer. J. Bot. 52: 495-505.

,-- and P. Q. Behrens. 1966. The luminous fungi. Pp. 203-223. In: Bioluminescence in Progress. Eds., F. H. Johnson and Y. Haneda. Princeton University Press, Princeton, New Jersey.

$\longrightarrow$, and W. D. McElroy. 1959. Light emission from extracts of luminous fungi. J. Bacteriol. 77: 249-250.

Berliner, M. D. 1961a. Diurnal periodicity of luminescence in three basidiomycetes. Science 134: 740.

$\rightarrow-1961 \mathrm{~b}$. Studies in fungal luminescence Mycologia 53: 84-90.

- 1963. The action of monochromatic ultraviolet radiation on luminescence in Armillaria mellea. Radiation Res. 19: 392-401.

$-\rightarrow-$, and P. B. Brand. 1962. Effects of monochromatic ultraviolet light on luminescence in Panus stypticus. Mycologia 54: 415-421.

Bothe, F. 1931. Uber das leuchten verwesender blatter und sein erreger. Planta 14: 752-765.

Calleja, G. B., and G. T. Reynolds. 1970a. The oscillatory nature of fungal luminescence. Trans. Brit. Mycol. Soc. 55: 149-168.

$\longrightarrow$, and - 1970b. Spatial distribution of light in luminescent fungal mycelia. Arch. Mikrobiol. 71: 31-39.

Cormier, M. J., and J. R. Totter. 1966. The apparent phosphorescence of a substance extracted from the mycelium of the luminous fungus, Omphalia flavida. Pp. 225-231. In: Bioluminescence in Progress. Eds., F. H. Johnson and Y. Haneda. Princeton University Press, Princeton, New Jersey.

Endo, M., M. Kajiwara, and K. Nakanishi. 1970. Fluorescent constituents and cultivation of Lampteromyces japonicus. Chem. Commun. 1970: 309-310.

Foerster, G. E., P. Q. Behrens, and R. L. Airth. 1965. Bioluminescence and other characteristics of $\mathrm{Col}$ lybia velutipes. Amer. J. Bot. 52: 487-495.

Funk, H. B., and T. A. Krulwich. 1964. Preparation of clear silica gels that can be streaked. J. Bacteriol. 88: 1200-1201.

Harvey, E. N. 1952. Bioluminescence. Academic Press, New York. 649 p.

Hastings, J. W. 1952. Oxygen concentration and bioluminescence intensity. 1. Bacteria and fungi. $J$. Cell. Comp. Physiol. 39: 1-30.

, and G. Weber. 1963. Total quantum flux of isotropic sources. J. Opt. Soc. Amer. 53: 1410 1415.

Isobe, M., D. Uyakul, and T. Goto. 1987. Lampteromyces bioluminescence-1. Identification of riboflavin as the light emitter in the mushroom, $L$. japonicus. J. Biolum. Chemilum. 1: 181-188.

- - $\longrightarrow$, and - 1988. Lampteromyces bioluminescence -2 . Lampteroflavin, a light emitter in the luminous mushroom, L. japonicus. Tetrahedron Lett. 29: 1169-1172.

Kamzolkena, O. V. 1982. Oscillation of bioluminescence in submerged culture of Armillaria mellea (Fr.) Kumm. Mikologiia Fitopatologiia 16: 323325.

- V. S. Danilov, and E. S. Egorov. 1983. The nature of luciferase from the bioluminescent fungus Armillariella. Doklady Akademii Nauk SSSR 271: 750-752.

Kuwabara, S., and E. C. Wassink. 1966. Purification and properties of the active substance of fungal luminescence. Pp. 233-245. In: Bioluminescence in Progress. Eds., F. H. Johnson and Y. Haneda. Princeton University Press, Princeton, New Jersey.

Lavelle, F., P. Durosay, and M. Michelson. 1972. Luminescence des champignons lumineux. $C . R$. Acad. Sci. Paris D 275: 1227-1230.

Leslie, J. F., and T. J. Leonard. 1979. Monokaryotic fruiting in Schizophyllum commune: phenoloxidases. Mycologia 71: 1082-1085.

McKenzie, H. A. 1974. pH and buffers. Pp. 475-506. In: Data for Biochemical Research. 2nd Ed. Eds., R. M. C. Dawson, D. C. Elliott, W. H. Elliott, and K. M. Jones. Oxford at the Clarendon Press. Oxford.

Macrae, R. 1937. Interfertility phenomena of the American and European forms of Panus stipticus (Bull.) Fries. Nature 139: 674.

1942. Infertility studies and inheritance of luminosity in Panus stipticus. Canad. J. Res. 20: $411-434$.

Molina, R., and J. G. Palmer. 1982. Isolation, maintenance, and pure culture manipulation of ectomycorrhizal fungi. Pp. 115-129. In: Methods and Principles of Mycorrhizal Research. Ed., N. C. Schenck. American Pathological Society, St. Paul, Minnesota.

Moore-Landecker, E. 1972. Fundamentals of the Fungi. Prentice-Hall, Inc., Englewood Cliffs, New Jersey.

Nakamura, H., Y. Kishi, and O. Shimomura. 1988. Panal: a possible precursor of fungal luciferin. Tetrahedron 44: 1597-1602.

Nicholson, W. L., and A. D. Robinson. 1983. Temperature sensitive mutations affecting extracellular 
phenoloxidase activity in Panus tigrinus. Mycologia 75: 176-179.

Shimomura, O. 1989. Chemiluminescence of panal (a sesquiterpene) isolated from the luminous fungus Panellus stipticus. Photochem. Photobiol. 49: 355-360.

Singer, R. 1986. The Agaricales in Modern Taxonomy. 4th Ed. Koeltz Books, Koenigsten, Germany. 981 p. +88 plates.

Smibert, R. M., and N. R. Krieg. 1981. General characteristics. Pp. 409-443. In: Methods for General Bacteriology. Ed., P. Gerhardt. American Society for Microbiology, Washington, D.C.

Sommers, L. E., and R. F. Harris. 1968. Routine preparation of silica gel media using silicate solutions of varying $\mathrm{pH}$. J. Bacteriol. 95: 1174.

Spruit-van der Burg, A. 1950. Emission spectra of luminous bacteria. Biochim. Biophys. Acta 5: 175178.
Stamets, P., and J. S. Chilton. 1983. The Mushroom Cultivator. Agarikon Press, Olympia, Washington $415 \mathrm{p}$.

Tan, K. K. 1978. Light-induced fungal development. Pp. 334-357. In: The Filamentous Fungi. Vol. 3. Eds., J. E. Smith and D. R. Berry.

Wassink, E. C. 1978. Luminescence in fungi. Pp. 171-197. In: Bioluminescence in Action. Ed., P. J. Herring. Academic Press, London. , and S. Kuwabara. 1966. Some notes on semilargescale cultivation of luminous fungi. Pp. 247264. In: Bioluminescence in Progress. Eds., F. H. Johnson and Y. Haneda. Princeton University Press, Princeton, New Jersey.

Accepted for publication October 22, 1989 